\title{
Hepatic artery involvement in polymyalgia arteritica
}

\author{
AL OGILVIE, PD JAMES, PJ TOGHILL \\ From the Departments of Medicine and Pathology, University Hospital, Queen's Medical Centre, \\ Nottingham N67 $2 U H$
}

SUMMARY Disturbances of liver function tests are common in polymyalgia arteritica, but the underlying liver lesion has not been defined. We report a patient who was demonstrated to have a giant cell arteritis involving both the hepatic and temporal arteries, and we discuss the possibility that such an arteritis involving the hepatic arteries is responsible for the abnormalities of liver function seen in this condition.

Disturbances of liver function tests, particularly raised alkaline phosphatase concentrations and impairment of Bromsulphthalein excretion, are commonly found in patients with polymyalgia arteritica. These abnormalities have been attributed to vascular changes in the liver ${ }^{12}$ although there has been no histopathological confirmation of this from biopsy material. We describe a patient with a granulomatous condition of both the hepatic and temporal arteries typical of polymyalgia arteritica.

\section{Case report}

A 69-year-old housewife was admitted for investigation with a five-month history of weight loss $(9 \mathrm{~kg})$, right sided abdominal pain, exertional dyspnoea and general lethargy. On direct questioning, she admitted to some headaches after a minor head injury five months before, which had been treated with ibuprofen. She had also received a course of cimetidine for the abdominal pain without relief. She had taken no other medication. Her previous medical history was unremarkable and her general health had otherwise been good.

On examination, she was a thin pale woman who was afebrile. Examination of the chest and cardiovascular system was normal. The liver was palpable $6 \mathrm{~cm}$ below the costal margin and was firm and smooth. Examination of the central nervous system was normal, and the temporal arteries were palpable, pulsating and non-tender.

Investigations showed: haemoglobin $11.0 \mathrm{~g} / \mathrm{dl}$; normochromic film with some mildly hypochromic cells; white blood cell count $9.2 \times 10^{9} / 1\left(9200 / \mathrm{mm}^{3}\right)$, normal differential. ESR (Westergren) (erythrocyte sedimentation rate) $92 \mathrm{~mm}$ in the first hour. Liver function tests: bilirubin $5 \mu \mathrm{mol} / 1$ (normal range 5-17

Accepted for publication 19 November 1980 $\mu \mathrm{mol} / 1(0 \cdot 3-1 \cdot 0 \mathrm{mg} / 100 \mathrm{ml}))$; alkaline phosphatase $1135 \mathrm{IU} / 1$ (normal range 46-190 IU/1); glutamyl pyruvate transferase $18 \mathrm{IU} / 1$ (normal range 2-24 IU/l); gamma glutamyl transpeptidase 93 IU/1 (normal range 4-28 IU/1); prothrombin ratio 1.00. Alkaline phosphatase isoenzymes were predominantly of liver origin. HBsAg (Hepatitis B surface antigen) was negative. Total protein $72 \mathrm{~g} / 1$ (normal range 63-78 g/l); albumin $29 \mathrm{~g} / 1$ (normal range 31-51 $\mathrm{g} / \mathrm{l})$. Urinalysis: negative for blood, sugar and protein. Urine culture: sterile. Barium meal, barium enema and intravenous pyelogram were all normal as was a ${ }^{99}$ Technetium isotopic liver scan. Antibodies against antinuclear, mitochondrial and smooth muscle antigens were absent, as were those to brucella, psittacosis, rickettsia and mycoplasma.

Laparotomy was performed. The liver was found to be enlarged with a normal biliary system. There was no other abnormality. A large wedge biopsy of liver was taken. The wedge biopsy specimen measured $4.5 \times 2.5 \times 2.2 \mathrm{~cm}$. Histological examination revealed a normal liver architecture with some fatty degeneration of liver cells. The significant abnormality was a granulomatous inflammation involving some small arteries in the portal tracts as well as larger septal arteries. The involved vessels showed a transmural inflammation with giant cells in their walls (Fig. 1). Elastic van Gieson's staining confirmed destruction of elastic lamina.

On the basis of these findings a temporal artery biopsy was subsequently performed. The specimen consisted of two fragments of white tissue both measuring $0.5 \mathrm{~cm}$ in length. Sections showed a small muscular artery in which there was a predominantly lymphocytic inflammatory infiltrate in the media of the vessel and numerous giant cells were also present (Fig. 2).

Elastic van Gieson's staining demonstrated destruction of the elastic lamina which was closely 

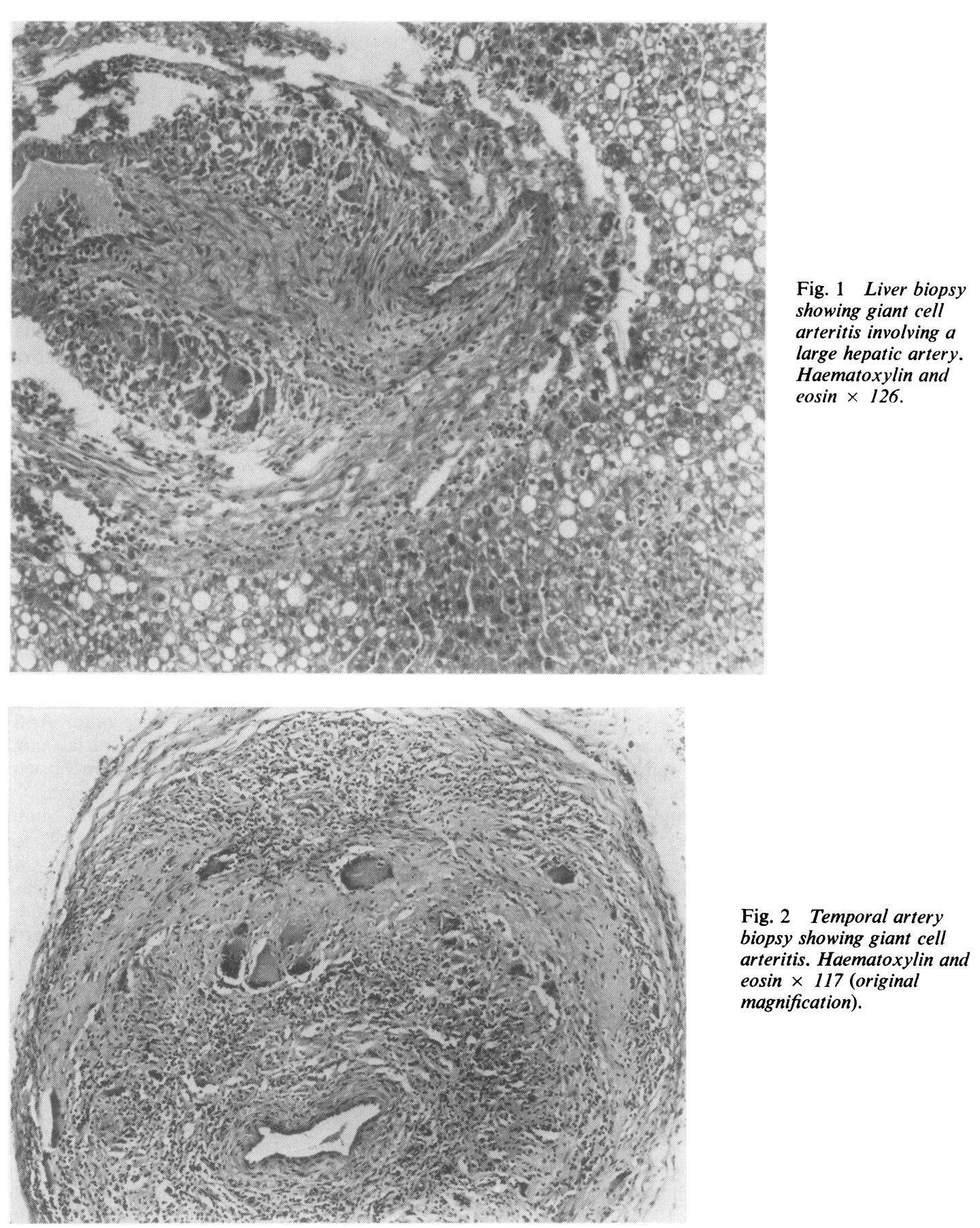

Fig. 2 Temporal artery biopsy showing giant cell arteritis. Haematoxylin and eosin $\times 117$ (original magnification).

associated with the giant cell reaction (Fig. 3). The overall appearances were typical of giant cell (temporal) arteritis and were identical to the histological changes seen in the hepatic arteries.
The patient was started on prednisolone $60 \mathrm{~m} \Omega$ daily, with a rapid fall of both ESR and alkaline phosphatase levels. At present (1 year later) she remains well on a maintenance dosage of $7.5 \mathrm{mg}$ 


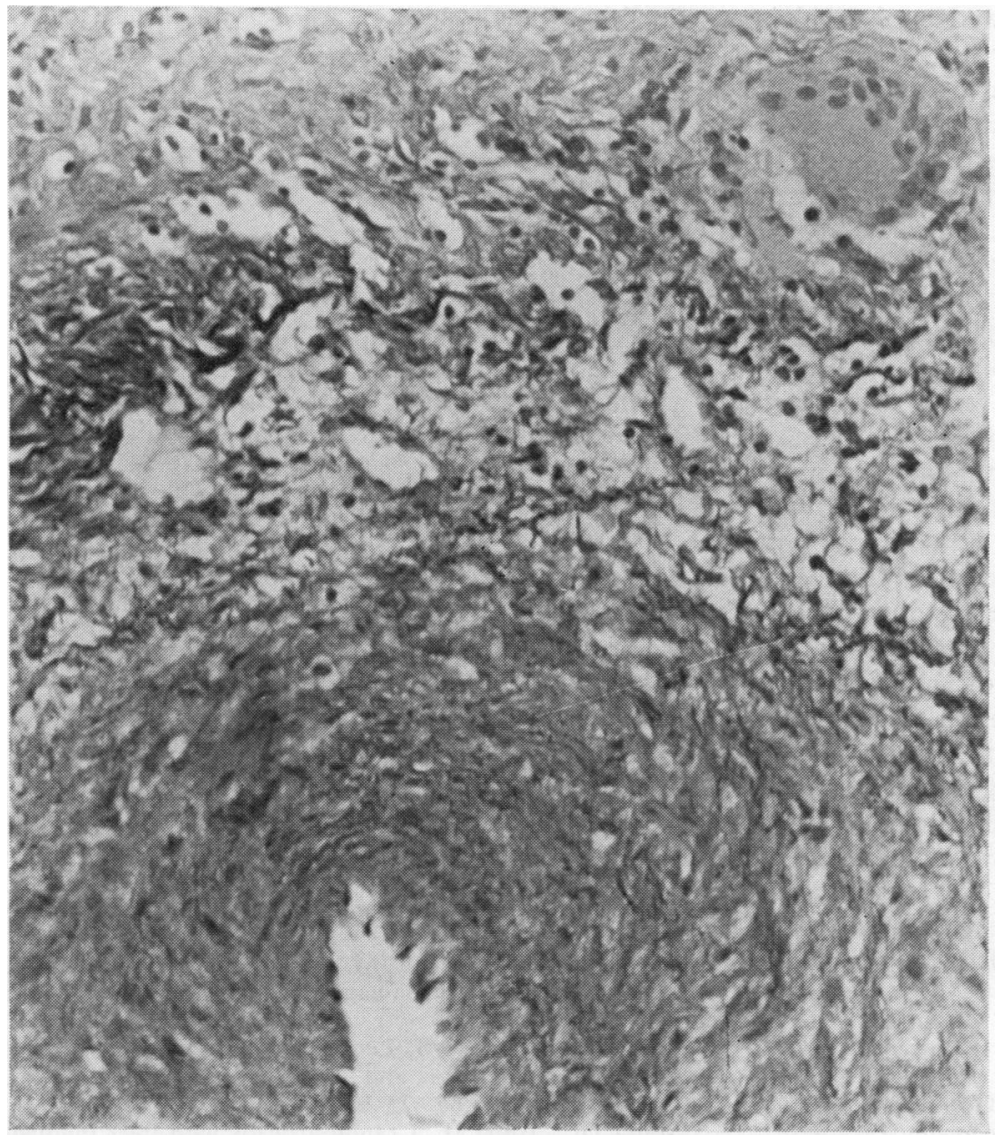

Fig. 3 Temporal artery biopsy showing destruction of the elastic lamina and giant cells. Elastic van Gieson's stain $\times 292$.

prednisolone per day; the blood count, ESR and liver function tests have all returned to normal.

\section{Discussion}

Temporal arteritis bears a close clinical and pathological relation to polymyalgia rheumatica with arteritis as the common link. The term polymyalgia arteritica has been proposed to embrace both these conditions. ${ }^{3}$ In our patient the presence of giant cell arteritis involving both the temporal and hepatic arteries and the prompt response to steroid treatment leave no doubt about the diagnosis of polymyalgia arteritica.

Abnormal liver function tests have been previously reported in both temporal arteritis and polymyalgia rheumatica, the major abnormalities being raised alkaline phosphatase concentrations and impaired Bromsulphthalein excretion. 4 The incidence of these abnormalities in published series varies from $9 \%$ to $100 \%$ with most recent series showing an incidence of about $60 \%{ }^{4}$ Despite the frequency of these changes the underlying liver lesion has not been satisfactorily defined.

Necropsies of patients dying in the acute phase of polymyalgia arteritica are rare, particularly since the widespread use of corticosteroid treatment. Arteritis of the hepatic vessels was demonstrated in one case in $1954,{ }^{5}$ but other postmortem studies have shown normal liver histology. ${ }^{6} \mathrm{~A}$ recent series of patients with disseminated visceral giant cell arteritis? included two with hepatic artery involvement; however, temporal arteries were not examined, and the author argued that this syndrome was distinct from temporal arteritis with visceral involvement.

Liver biopsies from patients with polymyalgia arteritica have hitherto failed to demonstrate hepatic artery involvement. One case with hepatic artery involvement was mentioned in a series of 37 patients with polymyalgia rheumatica but no further details were given. ${ }^{4}$ Single cases of granulomatous hepatitis have been reported in polymyalgia rheumatica ${ }^{8} 9$ and in temporal arteritis. ${ }^{1}$ Some features of chronic hepatitis have also been described in polymyalgia 
rheumatica. ${ }^{10}$ An association between polymyalgia rheumatica and primary biliary cirrhosis, ${ }^{11}$ has been claimed but was not confirmed in a large study of patients with primary biliary cirrhosis. ${ }^{12}$ Needle biopsy of the liver in polymyalgia arteritica has been generally unhelpful showing variable or inconsistent features. These include normal appearances, ${ }^{13} 14$ moderate bile stasis, ${ }^{14}$ fatty degeneration ${ }^{15}$ and nonspecific portal tract inflammatory infiltration. ${ }^{16}$ Electron microscopy ${ }^{17}$ showed changes predominantly in mitochondria and endoplasmic reticulum, but these were interpreted as non-specific and represented a reaction to cellular injury.

We propose that the underlying liver lesion in polymyalgia arteritica is an arteritis involving the hepatic arteries. This is supported by description of filling defects on isotopic liver scans in temporal arteritis which disappeared after steroid treatment. ${ }^{1819}$ These may represent hepatic infarcts, presumably as a result of occlusion of several arteries. The high concentrations of alkaline phosphatase often associated with polymyalgia arteritica presumably derive from bile duct lining cells damaged as a result of adjacent arteritis. Local ischaemia could also account for the many and varied histological appearances in earlier reports. ${ }^{14-17}$ Needle liver biopsies may also appear normal because of sampling errors and the segmental nature of the disease.

\section{References}

${ }^{1}$ Litwack KD, Bohan A, Silverman L. Granulomatous liver disease and giant cell arteritis. $J$ Rheumatol 1977;4:30712.

${ }^{2}$ Phillipe JM, Lavallard JF, Veyssier P. Atteinte hepatique au cours de la maladie de Horton. Nouv Presse Med 1978;7:1118-9.

${ }^{3}$ Hamrin B, Jonsson N, Landberg T. Arteritis in polymyalgia rheumatica. Lancet $1964 ; \mathrm{i}: 397-401$.

4 von Knorring J, Wasastjerna C. Liver involvement in polymyalgia rheumatica. Scand $J$ Rheumatol 1976;5 197-204.

${ }^{5}$ Heptinstall RH, Porter KA, Barkley H. Giant cell (tem poral) arteritis. Journal of Pathology and Bacteriolog $\underset{\mathrm{F}}{\mathrm{F}}$ 1954;67:507-19.

B Cooke WT, Cloake PCP, Govan ADT, Colbeck JC우 Temporal arteritis: a generalised vascular disease. $Q \Phi$ Med 1946:15:47-75.

7 Lie JT. Disseminated visceral giant cell arteritis. Am J Clip Pathol 1978;69:299-305.

${ }^{8}$ Long R, James $O$. Polymyalgia rheumatica and live@ి disease. Lancet 1974;i:77-9.

- Kosolcharoen P, Magnin GE. Liver dysfunction an $\overrightarrow{\dot{D}}$ polymyalgia rheumatica. A case report. $J$ Rheumatot 1976;3:50-3.

10 Thompson K, Roberts PF. Chronic hepatitis in poly myalgia rheumatica. Postgrad Med J 1976;52:236-8.

11 Robertson JC, Batstone GF, Loebl WY. Polymyalgia rheumatica and primary biliary cirrhosis. Br Med J 1978థ ii:1128.

12 Clarke AK, Galbraith RM, Hamilton EBD, Williams R Rheumatic disorders in primary biliary cirrhosis. An\& Rheum Dis 1978;37:42-7.

13 Hamilton CR, Shelley WM, Tumulty PA. Giant ce arteritis; including temporal arteritis and polymyalgia rheumatica. Medicine 1971;50:1-27.

14 Wadman B, Werner I. Observations on temporal arteritis Acta Med Scand 1972;192:377-83.

15 Dickson ER, Maldonado JE, Sheps SG, Cain JA. Systemi giant cell arteritis with polymyalgia rheumatica. reversible abnormalities of liver function. JAMA 1973224:1496-8.

16 Gibbs P. Polymyalgia rheumatica and liver disease. Lance 1974 ;i:351-2.

17 Terwindt VAM, Knoben JMAM. Polymyalgia rheumatic arteritis and hepatic damage. Acta Med Scand 1966;179 307-18.

${ }^{18}$ Ghose MK, Shensa S, Lerner PI. Arteritis of the age (giant cell arteritis) and fever of unexplained origin Am J Med 1976;60:423-36.

19 Mann DC, Toole JF. Cranial arteritis with liver involve ment. Stroke 1972;3:131-4.

Requests for reprints to: Dr AL Ogilvie, Department of Medicine, University Hospital, Queen's Medical Centre் Nottingham NG7 2UH, England. 